\title{
Evaluación de una estrategia de sensibilización para desestimular el uso de bolsas plásticas en usuarios de supermercados del municipio del Socorro (Santander)
}

Assessment of an awareness strategy to discourage the use of plastic bags by users of supermarkets in Socorro (Santander)

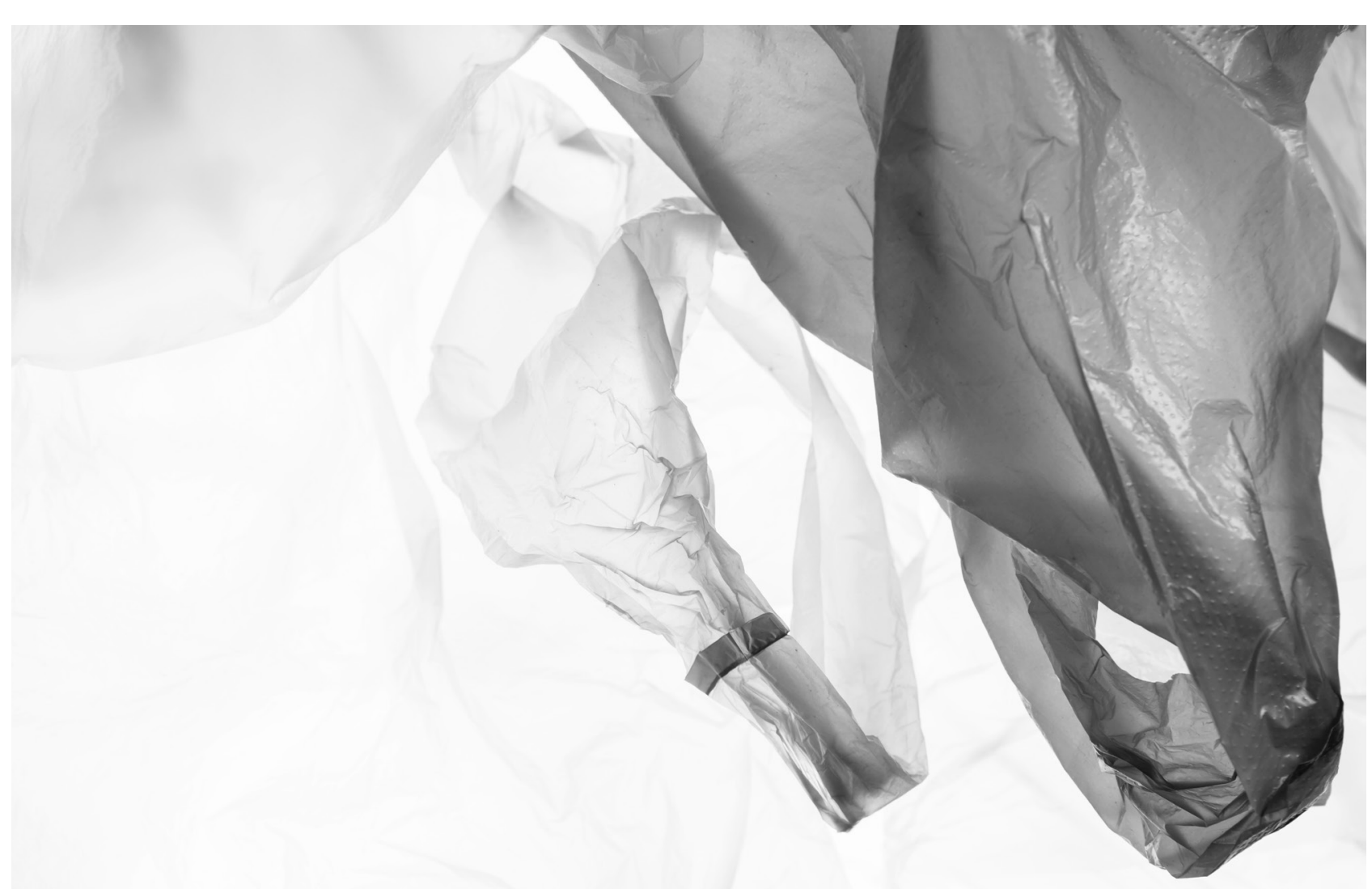




\title{
Evaluación de una estrategia de sensibilización para desestimular el uso de bolsas plásticas en usuarios de supermercados del municipio del Socorro (Santander) ${ }^{1}$
}

\author{
Assessment of an awareness strategy to discourage the use of \\ plastic bags by users of supermarkets in Socorro (Santander)
}

\author{
Adriana Milena Bolívar-Lamus²; Mónica Dayana Gamboa-Peña ${ }^{3}$, \\ Jenifer Dayana Granados-Núñez ${ }^{4}$, María del Pilar Guauque-Torres ${ }^{5}$
}

Artículo recibido en abril 23 de 2019; artículo aceptado en agosto 08 de 2019

\begin{abstract}
Este artículo puede compartirse bajo la Licencia Creative Commons Atribución-NoComercial-Compartirlgual 4.0 Internacional y se referencia usando el siguiente formato: Bolívar-Lamus, A. M., Gamboa-Peña, M. D., Granados-Núñez, J. D. \& Guauque-Torres, M. P. (2020). Evaluación de una estrategia de sensibilización para desestimular el uso de bolsas plásticas en usuarios de supermercados del municipio del Socorro (Santander). I+D Revista de Investigaciones, 15 (1), 7-18. DOI: https://doi.org/10.33304/revinv.v15n1-2020001
\end{abstract}

\section{Resumen}

En Colombia se generan más de 1.300 .000 toneladas de resinas poliméricas. De ellas el $56 \%$ se usa para la producción de empaques, como bolsas plásticas, cuya principal característica es el uso por tiempo reducido y por única vez. Esto aumenta la cantidad de material que se desecha con una biodegradabilidad mínima, lo que acentúa su impacto ambiental. Por esta razón, es necesario implementar diversas estrategias de sensibilización ambiental para desestimular el uso de bolsas plásticas. Para lograrlo, se estudió el impacto de diversas estrategias visuales en el municipio del Socorro (Santander), y se encontró que más del $80 \%$ de la población conoce las consecuencias del uso indiscriminado de bolsas plásticas, pero no implementan prácticas que disminuyan tal impacto. Asimismo, se encontró que el uso de estímulos visuales que apelan a respuestas no conscientes de los habitantes puede generar una disminución en la elección del uso de bolsas plásticas en el momento de la compra.

Palabras clave: Sensibilización ambiental, material plástico, contaminación medioambiental.

\footnotetext{
${ }^{1}$ Artículo de investigación experimental, de enfoque descriptivo, resultado de un proyecto de investigación formativa culminado, perteneciente al área de educación ambiental, desarrollado en el grupo de investigación GIAM-Z y financiado por la Universidad Libre, seccional Socorro (Colombia). Dirección: Campus Universitario Majavita. Tel.: (7) 727 6500, ext. 3875. Fecha de inicio: febrero de 2018. Fecha de terminación: junio de 2018.

${ }^{2}$ Estudiante, Metodología de la Investigación Científica, Universidad Libre de Colombia, seccional Socorro (Colombia). Dirección: Campus Universitario Majavita, Socorro, Santander, PBX: (7) 727 6500. Correo electrónico: adm.adriana.bolivar@gmail.com. ORCID ID: https://orcid.org/0000-0002-9269-7137 ${ }^{3}$ Estudiante, Metodología de la Investigación Científica, Universidad Libre de Colombia, seccional Socorro (Colombia). Dirección: Campus Universitario Majavita, Socorro, Santander, PBX: (7) 727 6500. ORCID ID: https://orcid.org/0000-0002-5167-2697. Correo electrónico: monicadgp19@gmail.com.

${ }^{4}$ Estudiante, Metodología de la Investigación Científica, Universidad Libre de Colombia, seccional Socorro (Colombia). Dirección: Campus Universitario Majavita, Socorro, Santander, PBX: (7) 727 6500. ORCID ID: https://orcid.org/0000-0002-9918-8626. Correo electrónico: dayanagranados74@gmail.com. ${ }^{5}$ Vinculada al Grupo de Investigación en Ingeniería Ambiental y Zootecnia GIAM-Z, Universidad Libre de Colombia, seccional Socorro (Colombia). Dirección: Campus Universitario Majavita, Socorro, Santander, PBX: (7) 727 6500. ORCID ID: https://orcid.org/0000-0003-2388-9642. Correo electrónico institucional: pilar.guauque@unilibre.edu.co.
} 
Adriana Milena Bolívar-Lamus, Mónica Dayana Gamboa-Peña, Jenifer Dayana Granados-Núñez, María del Pilar Guauque-Torres Evaluación de una estrategia de sensibilización para desestimular el uso de bolsas plásticas en usuarios de supermercados del municipio

\section{Abstract}

Colombia produces more than 1,300,000 tons of polymeric resins, of which $56 \%$ is used for the production of packaging such as plastic bags that are used for a short time and once only. This behavior increases the amount of material that is discarded with a minimum biodegradability, which accentuates its environmental impact. For this reason, it is necessary to implement various environmental awareness strategies to discourage the use of plastic bags. To that end, the impact of various visual strategies in Socorro (Santander) was studied and it was found that more than $80 \%$ of the population knows the consequences of the indiscriminate use of plastic bags, but does not implement practices that reduce such impact. Likewise, it was found that the use of visual stimuli that appeal to non-conscious responses of the locals could generate a decrease in the choice of the use of plastic bags at the time of purchase.

Keywords: Environmental awareness, plastic products, environmental pollution.

\section{Introducción}

En Colombia existe una normatividad que protege y vela por el cuidado y la sostenibilidad ambiental del territorio. Esta normatividad se consigna en la Constitución Política, que en sus artículos 79 y 80 consagra el derecho colectivo a gozar de un ambiente sano y el deber del Estado de proteger la diversidad e integridad del ambiente. Asimismo, el deber de planificar el manejo y aprovechamiento de los recursos naturales, a fin de garantizar su desarrollo sostenible, su conservación, restauración o sustitución, así como prevenir los factores de deterioro ambiental (Presidencia de la República de Colombia, 1991).

Por otra parte, el Decreto de Ley 2811 de 1974, en su artículo 8, expresa que "son factores que deterioran el ambiente, la contaminación de las aguas, el suelo y los demás recursos naturales renovables, la acumulación inadecuada de residuos y la alteración perjudicial o antiestética de paisajes naturales" (Presidencia de la República de Colombia, 1974). Además, el Ministerio de Ambiente y Desarrollo Sostenible, en un esfuerzo por disminuir la cantidad de bolsas plásticas que circulan en el mercado, expidió la Resolución 668 del 28 de abril de 2016, que reglamenta el uso racional de estas (Ministerio de Ambiente y Desarrollo Sostenible, 2016).

De acuerdo con el informe de la Asociación Colombiana de Industrias Plásticas (Acoplásticos) para 2015, Colombia poseía una capacidad instalada para la producción de 1.328 .000 toneladas de resinas poliméricas, de las cuales el $56 \%$ se usaba para producción de material de embalaje y empaque (DNP \& Tecnalia, 2017). Las resinas poliméricas tienen funcionalidades diferentes y su impacto ambiental varía de acuerdo con el ciclo de vida del producto, que incluye el procesamiento previo para la obtención de la resina, el maquinado para obtener un producto comercial, el tiempo de uso y el servicio del producto, así como su disposición final. Es justamente en estos dos últimos ítems en los que las bolsas plásticas y en general todo el material polimérico para embalajes y empaques representan un problema a escala mundial, debido a que son materiales con un tiempo de uso reducido (minutos/única vez), pero cuya disposición final es tema irresuelto (mínima biodegradabilidad que implica años y siglos de permanencia en el ambiente).

El plástico y en especial las bolsas elaboradas en este material son residuos altamente contaminantes para el planeta, puesto que la mayoría son sintetizados a partir de recursos no renovables, como el petróleo, y tardan alrededor de 400 a 1000 años en degradarse (Favara, Caballero, Morici \& Jakovcevic, 2013). Además, el modelo capitalista de consumo y acumulación de los habitantes de países occidentalizados ha generado un aumento constante del uso de este tipo de materiales, por su comodidad y versatilidad de aplicaciones, en desmedro de las condiciones ambientales (Martinez \& Porcelli, 2017).

Un porcentaje muy alto de las bolsas plásticas a las que se les da una mala disposición terminan contenidas en los mares y océanos que rodean los continentes, lo que ocasiona graves daños en los ecosistemas marinos, al ser consumidos por diversas especies, o generan contaminación en el medio, por la toxicidad de sus componentes. Según estimaciones de la UNEP (Programa de las Naciones Unidas para el Medioambiente), para el año 2050 los océanos tendrán más basura que peces (World Wide Foundation, 2017).

Por tanto, la problemática ambiental debe abordarse desde múltiples perspectivas y con el auspicio de todos los habitantes del planeta. En este sentido, la educación ambiental se convierte en el principio rector de la búsqueda de estrategias de prevención y remediación ambiental. La primera medida que se debe tener en cuenta es la de realizar diagnósticos de uso y percepción de los ciudadanos frente al tema. Con este objeto, investigadores en Buenos Aires, Argentina, preguntaron a 572 ciudadanos de dicha ciudad sobre el uso que daban a las bolsas plásticas y la posibilidad de sustituirlas por un modelo reutilizable. El resultado demostró que la mayoría de los encuestados utilizaron las bolsas en su 
Adriana Milena Bolívar-Lamus, Mónica Dayana Gamboa-Peña, Jenifer Dayana Granados-Núñez, María del Pilar Guauque-Torres Evaluación de una estrategia de sensibilización para desestimular el uso de bolsas plásticas en usuarios de supermercados del municipio del Socorro (Santander)

vida diaria para transportar productos adquiridos en el comercio y las reutilizaron para depositar los residuos que generan en sus casas (Matusevich \& Benayas, 2011).

De la misma forma, un estudio diagnóstico realizado en diferentes supermercados (grandes superficies) en la ciudad de Bogotá (Colombia) mostró que el $90 \%$ de los participantes declaraban desconocer los impactos negativos asociados al uso de bolsas plásticas, y además que un $40-60 \%$ de los encuestados admitió pedir más bolsas en el supermercado en el momento de la compra. La implementación de una cartilla ambiental sobre los impactos negativos del consumo excesivo de plásticos motivó que un 30-60\% de los encuestados declaren tener intenciones de reducir el uso de bolsas plásticas en sus compras habituales (Benavides León \& Ortiz, 2013).

Otro proyecto, esta vez de la comunidad de Marianza, Ecuador, propuso la acción comunitaria como una forma de disminuir el grado de contaminación ambiental existente en la comunidad. Para esto, aplicó una encuesta en la que el $93,3 \%$ de los participantes se comprometen a hacer parte del cambio para fortalecer los valores hacia el medioambiente (Romero-Ramírez \& Vélez-Ledesma, 2011).

Otra de las diferentes estrategias usadas en educación ambiental busca modificaciones en la conducta de los consumidores, a través del conocimiento de los fenómenos cognitivos que influencian la toma de decisiones. Uno de estos fenómenos es conocido como priming, y se define como "un proceso que activa conexiones particulares o asociaciones en la memoria, antes de que se lleve a cabo una acción consciente" (Kusev, van Schaik \& Aldrovandi, 2012). El priming afecta la toma de decisiones a través de estímulos (palabras, objetos, números) no relacionados con el procesamiento consciente de la información (Jain \& Kaur, 2004).

En este sentido, diferentes estudios sobre mercadeo indican que las decisiones inconscientes para elegir uno u otro producto están influenciadas por información procesada previamente o sutiles indicaciones en el ambiente en el momento de la compra. Estas sutiles indicaciones pueden ser una imagen, un texto, música o incluso un olor que activan las representaciones mentales de la percepción y modulan las representaciones mentales del comportamiento. Esto implica que la percepción puede modular el comportamiento (hacemos lo que vemos) en mayor o menor medida (Dijksterhuis, Smith, Baaren, Wigboldus \& Link, 2005).

Desde 1960 la preocupación medioambiental se ha instalado en las agendas de las sociedades occidentales, y la imagen como "archivo, registro, testigo, prueba - documento" ha sido una herramienta para la conformación de una conciencia ambiental a gran escala. Las imágenes legitiman ciertos discursos y permiten entender el pensamiento de la época y cómo cambia a través de los tiempos (Hollman, 2009).

La importancia de la imagen como forma de comunicación implica que la dinámica cognitiva de identificación y predisposición hacia una temática puntual recae en la información almacenada en la memoria y su correspondiente rememoración. Por tanto, la imagen puede funcionar como una unión que refuerza las asociaciones previas que tiene la memoria del individuo con una temática particular (Vargas, Mensa \& González, 2014).

Para observar la aplicabilidad de la estrategia de priming, haciendo uso de una imagen, un equipo investigador observó el comportamiento y la decisión de los clientes de una papelería de llevar bolsas plásticas en su compra cuando hay estímulos visuales presentes en el momento de la decisión. En la investigación se dispuso una imagen de un basurero para unos casos, y para otros una imagen libre de contaminación. Los resultados indicaron que hubo una disminución del $37 \%$ en el uso de las bolsas plásticas en los usuarios que fueron expuestos a la imagen relacionada con contaminación; además, se estableció que la influencia de la imagen fue más significativa en la decisión sobre el género femenino (Ferreriro et al., 2013).

De acuerdo con el Plan de Gestión Integral de Residuos Sólidos (PGIRS), para el año 2018 la generación de residuos sólidos del municipio del Socorro se estimó en un aproximado de $7.888,64$ toneladas al año, con una población de 35.565 habitantes. La mayoría de las viviendas que componen el casco urbano del municipio pertenecen al estrato socioeconómico dos (según información de la empresa de acueducto y alcantarillado); el $14 \%$ de sus residuos sólidos generados son inorgánicos, y de ellos, el $33,17 \%$ son plásticos. Aunque es imposible eliminar el daño que se le ha causado al medioambiente a lo largo de estos años, se pueden adoptar medidas para reducir el uso de este material contaminante (Alcaldía Municipal de El Socorro Santander, 2018).

Se estima que el desconocimiento de los impactos ambientales asociados al uso indiscriminado de bolsas plásticas en los habitantes del municipio del Socorro puede relacionarse con la elección del uso (o no) de bolsas en el momento de la compra. Es por ello que se planteó evaluar experimentalmente estrategias de sensibilización para desestimular el uso de bolsas plásticas en los usuarios de los supermercados Milca y Mercaexpress, puesto que son algunos de los supermercados con mayor concurrencia de compradores. Para la realización de este trabajo se hizo un diagnóstico inicial sobre la cantidad de bolsas entregadas en los supermercados en los días con mayores ventas, seguido del diseño de estrategias de sensibilización visuales relacionadas con la contaminación generada por el uso 
Adriana Milena Bolívar-Lamus, Mónica Dayana Gamboa-Peña, Jenifer Dayana Granados-Núñez, María del Pilar Guauque-Torres Evaluación de una estrategia de sensibilización para desestimular el uso de bolsas plásticas en usuarios de supermercados del municipio

de bolsas plásticas. Finalmente, se realizó una evaluación del impacto en las decisiones de los usuarios gracias a las estrategias mencionadas.

\section{Metodología}

\section{Tipo de estudio}

El tipo de estudio desarrollado es experimental-descriptivo, ya que se pretende observar si existen cambios en el comportamiento de los usuarios de supermercados (uso de bolsas plásticas), cuando existe un estímulo visual cerca que muestre el alto impacto ambiental de estos materiales. Se realizaron dos actividades complementarias. En la primera el objetivo fue observar el uso de bolsas plásticas por parte de los usuarios de supermercados en el momento del pago de sus compras en presencia o ausencia de un estímulo visual. Para esto, se realizó un diseño de experimentos tipo pre- y posprueba con observación y listas de chequeo. La segunda actividad implicó conocer la percepción ciudadana sobre el impacto ambiental después de la compra, cuando los usuarios ya han salido de los establecimientos y llevan sus productos en una bolsa plástica. En este caso se desarrolló un diseño de experimentos semiexperimental con única medición usando un cuestionario. Luego de tener el registro completo de los datos recolectados, se elaboró una base de datos en Excel, que se analizó con ayuda del complemento estadístico Megastat.

\section{Participantes}

Para el análisis del comportamiento frente a la estrategia visual en el momento de la compra, y teniendo en cuenta que la población a analizar la conformaron todos los posibles usuarios de supermercados ubicados en el sector San Victorino del municipio del Socorro, se utilizó un muestreo no probabilístico que implicó analizar únicamente los comportamientos de usuarios de los dos supermercados con mayor afluencia de público en los días de mayor venta (días de mercado, horario: 9:00 a. m. -11 a. m.). El total de participantes en los diferentes días de análisis fue de aproximadamente 200 personas. En presencia del estímulo visual se registró la conducta de 73 clientes, y bajo la condición ausencia de estímulo visual, se registró el comportamiento de 120 clientes. Para el análisis del comportamiento frente a la estrategia visual después de la compra se usó también un muestreo no probabilístico, usando como criterio principal de elección de los participantes el que estuviera realizando compras y tuviera bolsas plásticas como medio de transporte de sus productos. El total de participantes para este caso fue de 100 personas.

\section{Materiales e instrumentos}

Los instrumentos de recolección de la información fueron listas de chequeo y cuestionarios a usuarios con preguntas cerradas y abiertas. Estas se crearon tomando como base las utilizadas en los trabajos de Matusevich y Benayas (2011), así como las del trabajo realizado por Benavides León y Ortiz (2013).

\section{Encuesta}

Para el análisis del comportamiento frente a la estrategia visual en el momento de la compra, se usó una lista de chequeo que contenía información sobre edad aproximada del(la) comprador(a); género; si asistían una o más personas; cantidad de productos comprados; número de bolsas utilizadas; si el(la) comprador(a) traía alternativas para el transporte de los productos comprados; si el(la) comprador(a) pidió bolsas o las rechazó cuando el(la) cajero(a) se las ofreció.

Para el análisis del comportamiento frente a la estrategia visual después de la compra, se usó un cuestionario en el que se recolectó información sobre género, edad, nivel educativo, ocupación, hábitos de consumo diario de material plástico, conocimiento sobre el impacto ambiental asociado a su uso, así como posibles estrategias para remediarlo.

\section{Observación natural}

Se realizó trabajo de campo en diferentes momentos para identificar los lugares de mayor afluencia de público durante los jueves y los domingos (días de mercado); se determinaron puntos de instalación de los estímulos visuales y se obtuvieron permisos para hacer la investigación con las directivas de los negocios seleccionados y la administración municipal. Para el análisis en el momento de la compra en los días elegidos, se realizaron dos momentos de observación con lista de chequeo. El primer momento se realizó sin estímulo visual, mientras que en el segundo momento, se introdujo el estímulo visual en los puntos de pago de los supermercados seleccionados.

\section{Procedimiento}

El uso de estímulos visuales fue aplicado en dos instancias:

Estímulos visuales en el momento de la compra: Se siguió la metodología descrita por Ferreiro et al. (2013). Se identificaron brevemente los lugares de mayor afluencia de público. Se realizó un análisis diagnóstico con lista de chequeo sin estímulos visuales (fase 1). El mismo procedimiento fue seguido mostrando en el punto de pago una imagen (Figuras 1 y 2 ) relacionada con el impacto ambiental derivado del uso indiscriminado de bolsas plásticas (fase 2). En los dos momentos se evaluó la preferencia de los clientes hacia el uso de bolsas plásticas para el transporte de sus productos. 


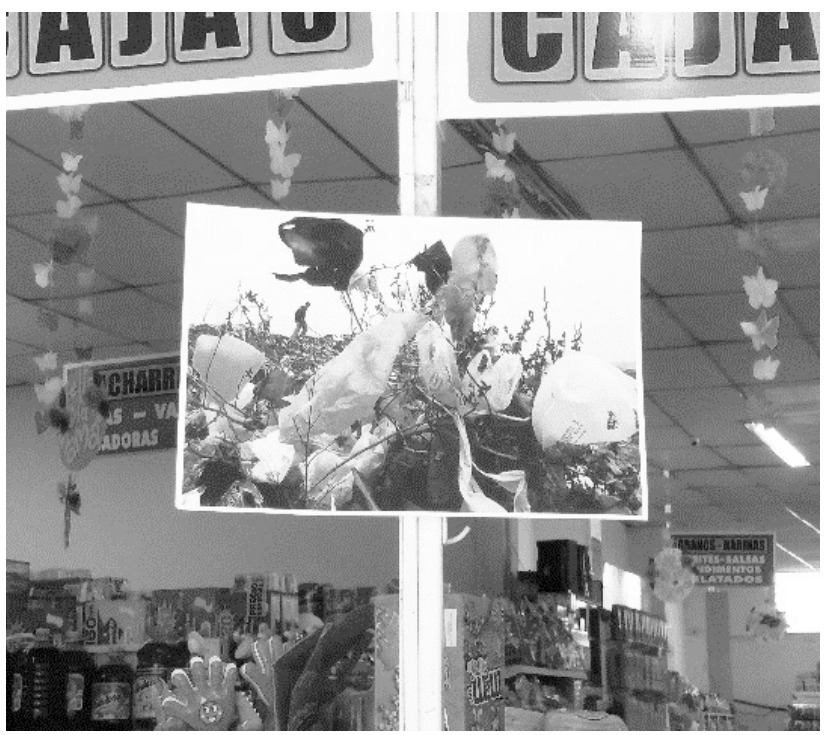

Figura 1. Instalación de imagen utilizada como estímulo, ubicada en las cajas de pago, para mostrar el impacto generado por las bolsas plásticas en el ambiente. Fuente: Autores.

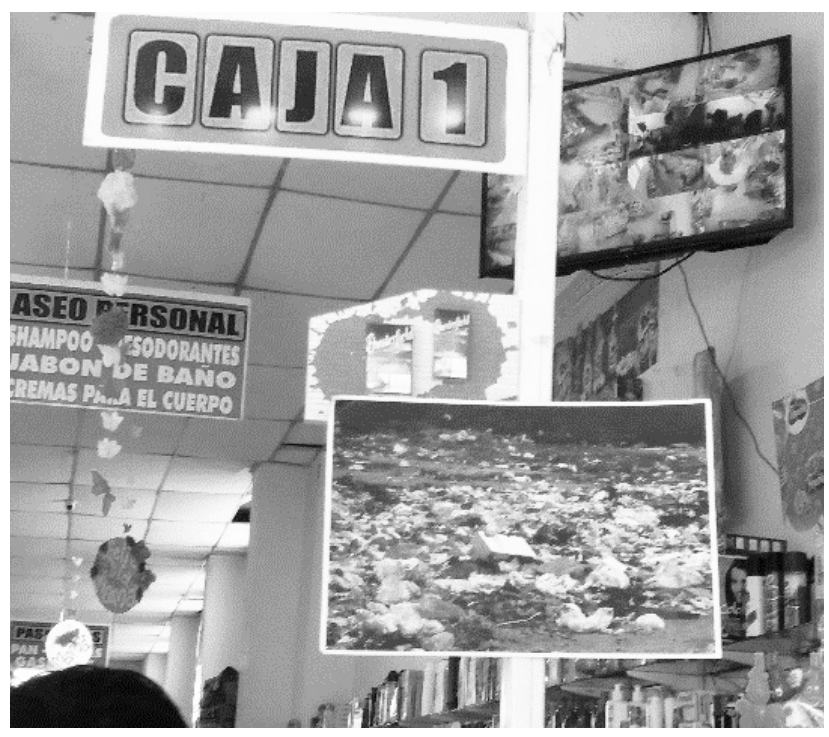

Figura 2. Instalación de imagen usada en el estudio como herramienta visual que ejemplifica el impacto ambiental del uso indiscriminado de bolsas plásticas en el ambiente. Nota: En el estudio, la pareja de fotografías se presentó a todo color, en cada caja de pago, con tamaño aproximado de $30 \times 35 \mathrm{~cm}$. Fuente: Autores.

Estímulos visuales en la calle después de la compra: Se instaló un globo terráqueo de aproximadamente $1,5 \mathrm{~m}$ de diámetro hecho con bolsas plásticas provenientes de la planta de reciclaje de la Universidad Libre, con un póster que contenía información sobre la problemática ambiental a una altura aproximada de $2 \mathrm{~m}$, para motivar el intercambio de bolsas plásticas por bolsas reutilizables gentilmente donadas por la Corporación Autónoma de Santander (CAS) y la Universidad Libre (Figura 3). Las personas que hicieron parte del intercambio respondieron las preguntas del cuestionario.

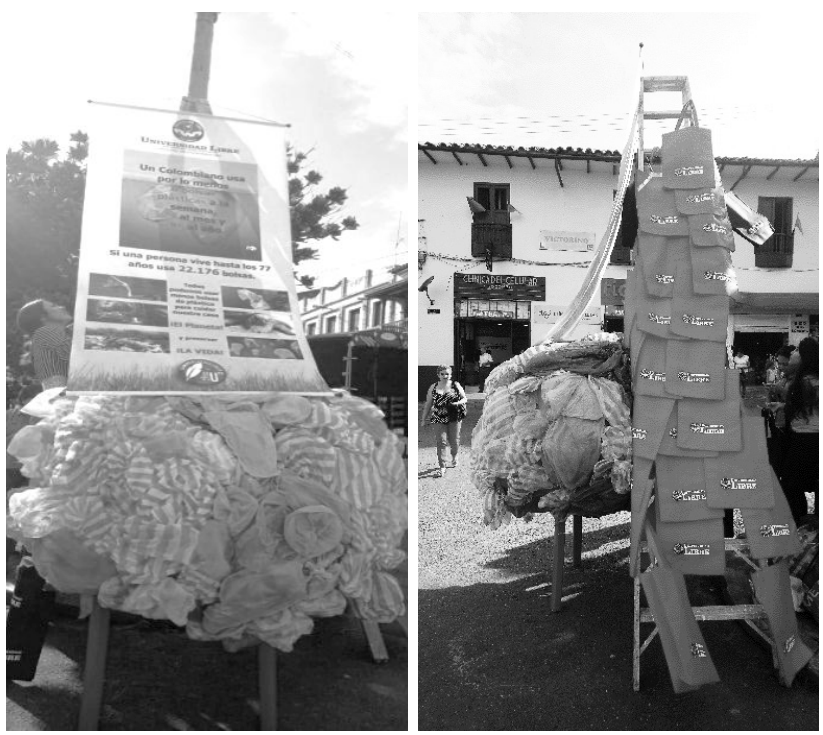

Figura 3. Globo terráqueo y póster. Nota: Instalación en el sector San Victorino (Socorro, calle $\left.13 \mathrm{n} .^{\circ} 16\right)$. Globo terráqueo hecho con bolsas plásticas reutilizadas, póster con información y bolsas reutilizables para intercambio. Fuente: Autores.

\section{Resultados}

Se identificaron los supermercados Milca (carr.a 16 n. ${ }^{\circ}$ 12-21) y Mercaexpress (carr.a 16 n. ${ }^{\circ}$ 12-68) como los supermercados con mayor afluencia de público en los días de mercado (jueves y domingo, 9:00 a. m.-11 a. m.). Los resultados derivados del análisis de las listas de chequeo para el momento de la compra permitieron identificar que la edad aproximada de los usuarios que realizan compras en el supermercado Milca los jueves, para la primera fase, se encontró en su mayoría entre los 40 y 50 años (31\%), seguido de 30 y 40 años $(23 \%)$; y para la segunda fase, un $37 \%$ corresponde a personas con edades entre los 50 y 60 años, seguido de 30-40 y 40-50 años, con porcentajes de $19 \%$ y $18 \%$, respectivamente.

Para el supermercado Mercaexpress, la edad aproximada de los usuarios que realizaron compras en el mismo día fue, para la primera fase, en su mayoría entre los 40 y 60 años ( $32 \%$ para cada rango de 10 ); y para la segunda fase, un $32 \%$ corresponde a personas con edades entre los 30 y 40 años, seguido de $50-60$, con un porcentaje de $20 \%$.

Las gráficas presentadas solo se refieren a las indicaciones en la lista de chequeo más relacionadas con las variables de estudio. La variable que se refiere a la decisión de llevar o no bolsa se relaciona con la cantidad de productos que se compran (ver Gráficas 1 y 2 para el supermercado Milca, y Gráficas 3 y 4 para el supermercado Mercaexpress). Además, influye si se cuenta o no con otro medio de empaque para transportar los productos y si los cajeros preguntan al usuario si desea o no una bolsa plástica (ver Tabla 1).

Durante el proceso de observación en los supermercados, 
en ambas etapas (con estímulo y sin estímulo) se pudo apreciar que la mayoría de las personas no llevan un medio para transportar sus compras (bolsa de tela, fique, canastos, etc.), sino que esperan que les sea suministrado en el supermercado; y una parte del porcentaje de clientes que sí lo llevan no le dan el uso adecuado. Es el caso de usuarios que aún llevando otra alternativa reciben o solicitan la bolsa plástica y la guardan dentro de dicha alternativa, de modo que esta les resulta inútil.

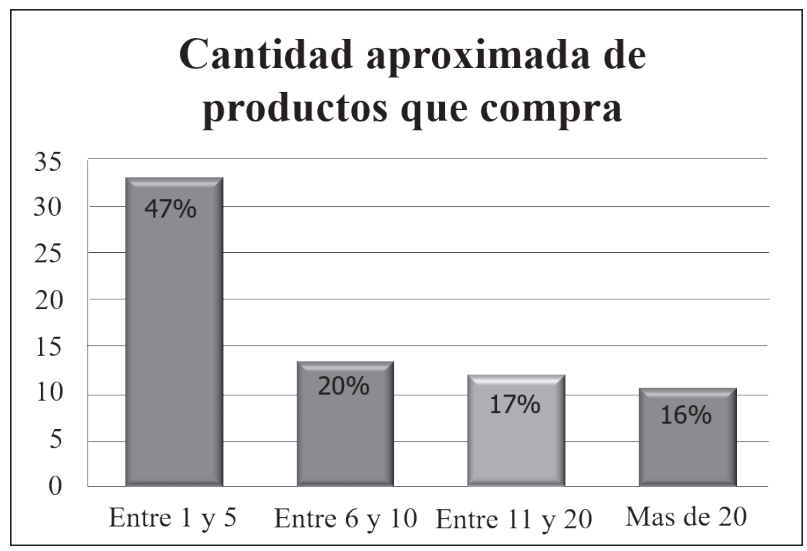

Gráfica 1. Sup. Milca, fase 1. Fuente: Autores.

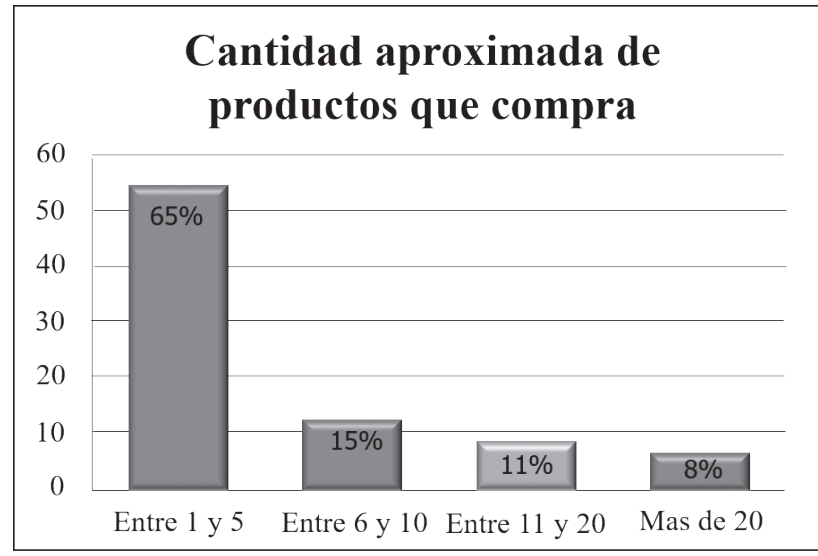

Gráfica 2. Sup. Milca, fase 2. Fuente: Autores.

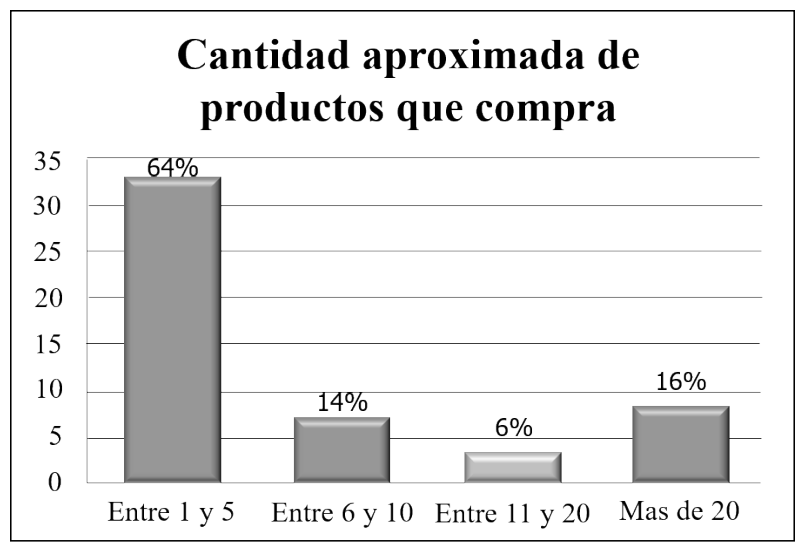

Gráfica 3. Sup. Mercaexpress, fase 1. Fuente: Autores.

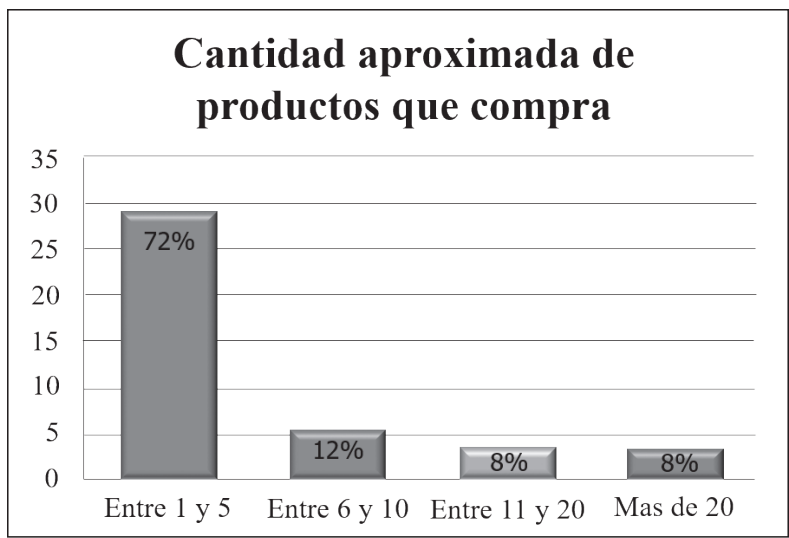

Gráfica 4. Sup. Mercaexpress, fase 2. Fuente: Autores.

Tabla 1

Resultados tabulados de las listas de chequeo en las fases 1 y 2

\begin{tabular}{|c|c|c|c|c|c|c|c|c|}
\hline \multirow{3}{*}{ PREGUNTA } & \multicolumn{4}{|c|}{$\begin{array}{c}\text { SUPERMERCADO MILCA } \\
(\%)\end{array}$} & \multicolumn{4}{|c|}{$\begin{array}{l}\text { SUPERMERCADO } \\
\text { MERCAEXPRESS (\%) }\end{array}$} \\
\hline & \multicolumn{2}{|c|}{$\begin{array}{c}\text { Sin } \\
\text { estímulo }\end{array}$} & \multicolumn{2}{|c|}{$\begin{array}{c}\text { Con } \\
\text { estímulo }\end{array}$} & \multicolumn{2}{|c|}{$\begin{array}{c}\text { Sin } \\
\text { estímulo }\end{array}$} & \multicolumn{2}{|c|}{$\begin{array}{c}\text { Con } \\
\text { estímulo }\end{array}$} \\
\hline & SI & NO & SI & NO & SI & NO & SI & NO \\
\hline $\begin{array}{l}\text { ¿El cliente } \\
\text { trajo bolsa } \\
\text { reutilizable, } \\
\text { canasto u otro } \\
\text { medio de } \\
\text { empaque } \\
\text { para el } \\
\text { transporte de } \\
\text { sus compras? }\end{array}$ & 10 & 90 & 13 & 87 & 14 & 86 & 10 & 90 \\
\hline $\begin{array}{l}\text { ¿El cajero } \\
\text { empacó en } \\
\text { bolsa plástica } \\
\text { sin preguntar } \\
\text { al cliente? }\end{array}$ & 63 & 37 & 68 & 32 & 80 & 20 & 82 & 18 \\
\hline
\end{tabular}

Fuente: Autores.

Otra situación relevante en el proceso, es el comportamiento que adoptan los cajeros de los supermercados al suministrar las bolsas de plástico a los clientes, sin consultar con ellos si quieren o no llevarlas; incluso el hecho de que en algunos casos el cliente rechaza la bolsa y el cajero o empacador hace caso omiso a esta petición. Otro suceso frecuente se enfoca en que el cajero no ofrece las alternativas con que cuenta el supermercado para sustituir la bolsa plástica, como las bolsas de tela y las cajas de cartón; además, el cajero no observa si la persona trae un medio para llevar sus compras.

En general se observan comportamientos similares de los usuarios en los dos supermercados y en las dos fases de observación.

En las Gráficas de la 5 a la 8, se muestra la incidencia del estímulo visual en las fases 1 y 2 del presente estudio. Para el supermercado Milca, la variación fue 
del $16 \%$, pasando del $80 \%$ al $64 \%$, y para el caso del supermercado Mercaexpress, la variación fue del $21 \%$, pasando del $86 \%$ al $65 \%$. La cifra de bolsas per cápita para el caso del supermercado Milca fue de 1,08 por día, y para Mercaexpress fue de 1,13 bolsas.

El análisis de las variables relacionado con el género de los participantes del estudio permitió evidenciar que en el supermercado Milca, en las fases 1 y 2 (sin estímulo y con estímulo visual, respectivamente), el $81 \%$ de las mujeres llevó bolsa, de las cuales 42 mujeres correspondieron a la fase 1, y 32, a la fase 2. Para el caso de los hombres, en la fase 1 (sin estímulo) el porcentaje que llevó bolsa plástica fue de $79 \%$, de un total de 28 , y para la fase 2 (con estímulo), de 21 hombres, el $38 \%$ llevó bolsa plástica.

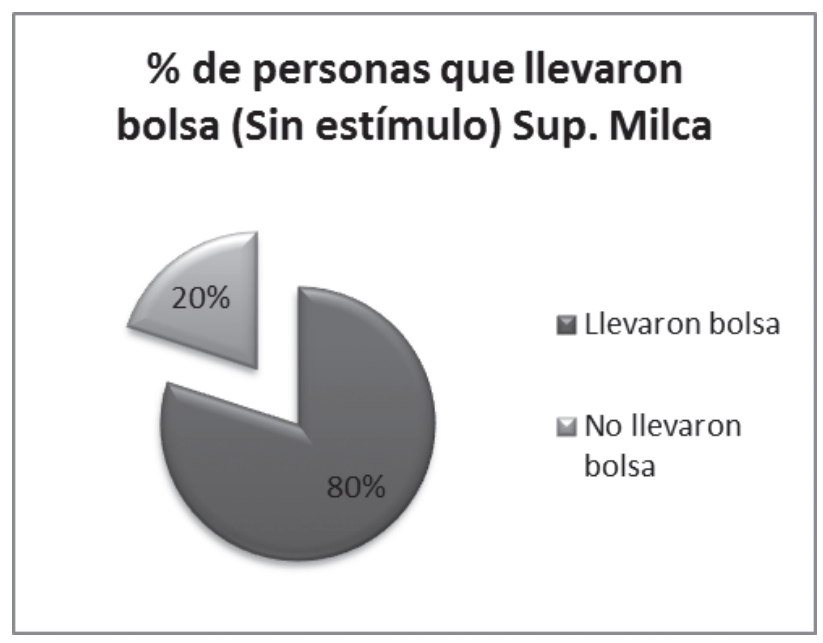

Gráfica 5. Personas que llevaron bolsa sin estímulo. Fase 1, Milca. Fuente: Autores.

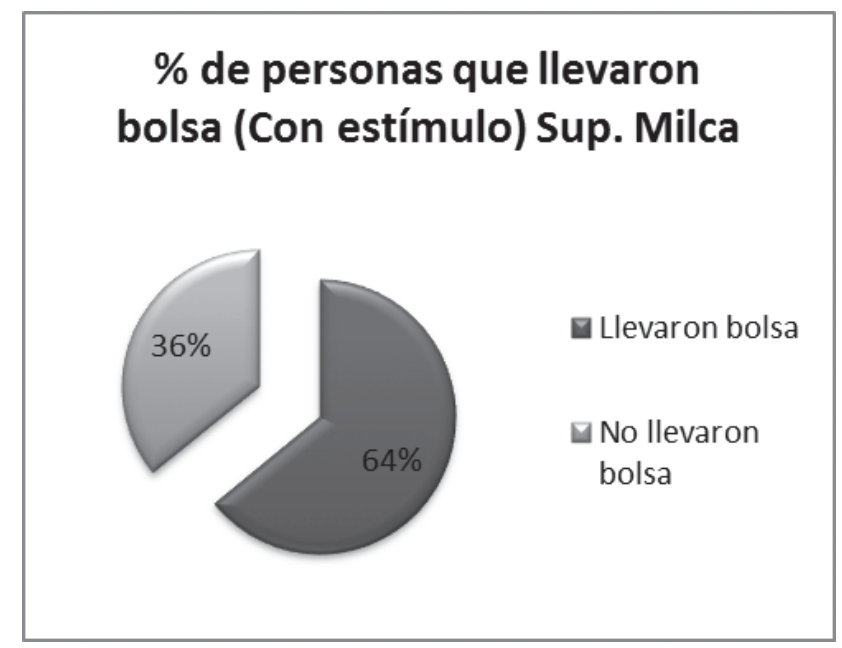

Gráfica 6. Personas que llevaron bolsa con estímulo. Fase 2, Milca. Fuente: Elaboración propia.

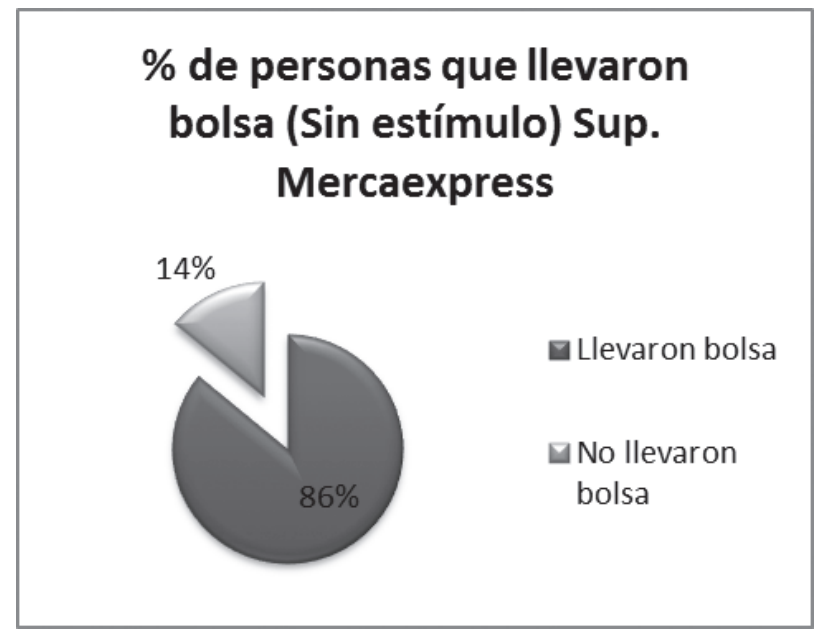

Gráfica 7. Personas que llevaron bolsa sin estímulo. Fase 1, Mercaexpress. Fuente: Elaboración propia.

\section{$\%$ de personas que llevaron bolsa (Con estímulo) Sup. Mercaexpress}

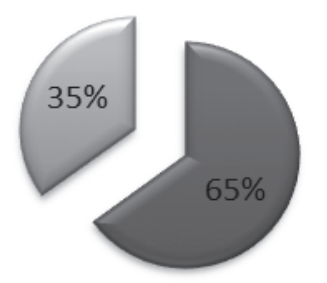

- Llevaron bolsa

No llevaron bolsa

Gráfica 8. Personas que llevaron bolsa con estímulo. Fase 2, Mercaexpress. Fuente: Elaboración propia.

En el supermercado Mercaexpress, se obtuvo la siguiente información: en la fase 1 (sin estímulo) el $93 \%$ de las mujeres llevó bolsa, de 29 mujeres en total, y para la fase 2 (con estímulo) el porcentaje fue de $67 \%$, de 12 mujeres observadas. Para el caso de los hombres, en la fase 1 (sin estímulo) el porcentaje que llevó bolsa plástica fue de $76 \%$, de un total de 21 , y para la fase 2 (con estímulo), de 8 hombres, el $62 \%$ llevó bolsa plástica.

Los resultados derivados del análisis de las encuestas para después de la compra, indicaron una proporción casi equitativa entre hombres (41\%) y mujeres (59\%) encuestados, con prevalencia de edades entre los 31 y 60 años (53\%). Con respecto al nivel de escolaridad, la mayoría de los encuestados terminaron la secundaria (44\%), seguidos por aquellos que terminaron la primaria (33\%) y algunos que culminaron la etapa universitaria (16\%).

Frente a la pregunta por el nivel de conocimiento que 
tienen los encuestados sobre los daños ambientales ocasionados por el uso excesivo de bolsas plásticas, el $83 \%$ manifestaron una respuesta positiva, mientras que un $17 \%$ los desconocen. Del $83 \%$ que respondió afirmativamente solo un $18 \%$ de la población no puede dar ejemplos de cuáles son dichos impactos en el medioambiente (ver Gráfica 9). Esto indica que indistintamente del género, edad o nivel de escolaridad, la comunidad conoce la problemática ambiental. Sin embargo, este porcentaje contrasta con los datos proveídos por el Plan de Gestión de Residuos Sólidos del Socorro (PGIRS- 2016), que indican que el $33 \%$ de los residuos inorgánicos que llegan a disposición final son de plástico.

Para conocer los hábitos de consumo de las personas encuestadas, se identificó que la mayoría de los ciudadanos declaran que consumen entre 0 y 5 bolsas semanalmente (ver Gráfica 10), y al ser interrogados sobre el destino de las bolsas plásticas una vez que las llevan a casa, el $72 \%$ respondió que las reutiliza; el $26 \%$ las tira a la basura y el $2 \%$ restante no contestó. El uso más común es el de emplearlas como bolsas para basura.

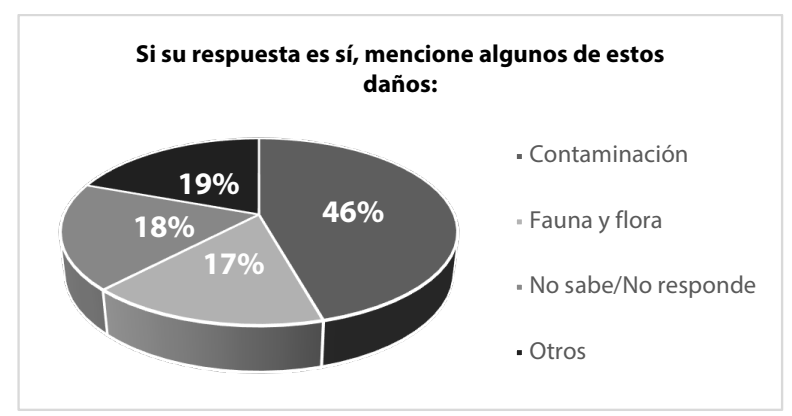

Gráfica 9. Conocimiento de daños ambientales. Fuente: Autores.

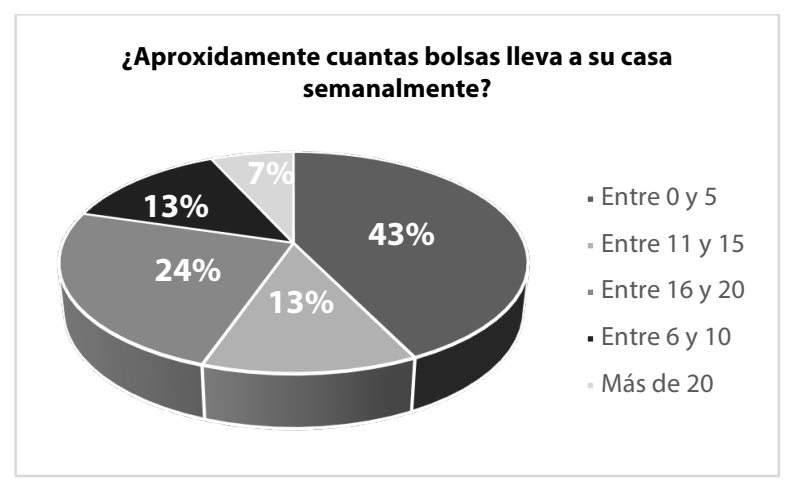

Gráfica 10. Hábitos de consumo de bolsas plásticas/semana. Fuente: Autores.

Finalmente, el $97 \%$ de los encuestados declaró estar dispuesto a dejar de usar bolsas plásticas, y de ellos el $78 \%$ estaría dispuesto a usar bolsas reutilizables para sus compras. La Gráfica 11 evidencia las respuestas de los encuestados frente a la pregunta por las alternativas de empaques para el transporte de sus productos, entre las que sobresale la recuperación del fique como material biodegradable y reutilizable. Vale la pena aclarar que la categoría "otros" se refiere a respuestas no relacionadas, como "porque contaminan" o"reutilizar las bolsas plásticas".

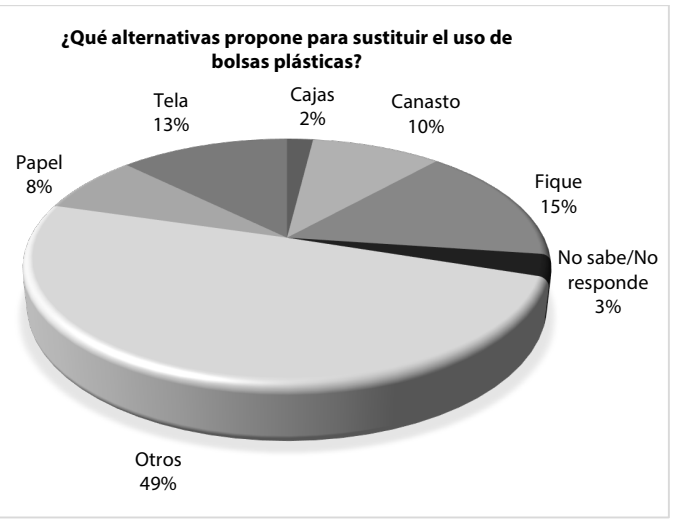

Gráfica 11. Alternativas a la bolsa plástica. Fuente: Elaboración propia.

\section{Discusión y conclusiones}

A menudo se afirma que el desconocimiento de los daños ambientales asociados al uso indiscriminado de plásticos es la principal causa que mantiene un crecimiento constante de la problemática. Es por esto que la metodología usada para el presente trabajo buscó brindar información consciente, pero también apelar a la respuesta inconsciente que puede generarse a partir de diferentes imágenes.

En el estudio realizado por Ferreiro et al. (2013), el porcentaje de personas que llevó bolsa plástica disminuyó en la condición de contaminación, pasando de $52 \%$ a $37 \%$. Del mismo modo ocurrió con la presente investigación, en que la cifra de personas que llevaron bolsa plástica al ser expuestas al estímulo visual disminuyó para las dos muestras (ver Gráficas de la 5 a la 8). Para el supermercado Milca, la variación fue del $16 \%$, mientras que para Mercaexpress la variación fue del $21 \%$. Se observó que la presencia de imágenes asociadas a las problemáticas ambientales derivadas del uso excesivo de bolsas plásticas puede activar las representaciones mentales asociadas a la percepción de un impacto negativo, y de esta forma modular las representaciones mentales asociadas a un comportamiento proambiental. Es importante señalar que la imagen solo refuerza asociaciones previas que tienen los individuos con temáticas particulares, lo que en el caso del presente estudio implica que los individuos analizados han observado previamente y conocen de antemano las problemáticas asociadas al exceso de bolsas plásticas en el medioambiente (Dijksterhuis et al., 2005; Vargas et al., 2014).

Estos resultados están relacionados con un estudio realizado en cuatro panaderías de la ciudad Satélite 
Adriana Milena Bolívar-Lamus, Mónica Dayana Gamboa-Peña, Jenifer Dayana Granados-Núñez, María del Pilar Guauque-Torres Evaluación de una estrategia de sensibilización para desestimular el uso de bolsas plásticas en usuarios de supermercados del municipio del Socorro (Santander)

Santa Rosa, Callao, en Perú, que pretendía establecer una relación entre el efecto de la sensibilización ambiental en los clientes de estas panaderías, mediante imágenes, charlas y alternativas para reemplazar las bolsas de plástico y el consumo de bolsas en cada compra. De los resultados obtenidos mediante la observación y la aplicación de encuestas a 240 clientes de las panaderías, se pudo determinar que las personas respondieron positivamente ante los estímulos ambientales aplicados, lo que redujo la cantidad de bolsas utilizadas en un $5,6 \%, 4,7 \%, 3,3 \%$ y $2,3 \%$ en las panaderías $1,2,3$ y 4 , respectivamente; pero además, para la panadería 3 el estímulo que resultó más efectivo fue el de la imagen, que se aplicó durante las semanas 1 y 4 , mostrando reducciones del $0,37 \%$ y $0,64 \%$ en esta panadería (Seijas Rivera, 2018).

Ohtomo y Ohnuma (2014) realizaron una investigación en cuatro supermercados de tamaño medio en Hokkaido, Japón, para identificar posibles cambios conductuales, en muchos casos inconscientes, con tan solo recibir un aviso; es decir, una señal que les recuerda la conciencia hacia una acción, en este caso proambiental. Para dicho estudio, el aviso consistió en preguntar a los clientes si querían llevar o no bolsa plástica al momento de pagar sus compras. Al igual que en la presente investigación, se realizó una fase previa de control sin ninguna intervención, y los datos fueron recolectados mediante observación y cuestionarios. El análisis de datos mostró que la intervención ocasionó una reducción del $5 \%$ en la cantidad de personas que llevaron bolsas de plástico, y al igual que en los supermercados Milca y Mercaexpress, al exponer el estímulo visual la tendencia a rechazar las bolsas de plástico mejoró significativamente (Ohtomo \& Ohnuma, 2014).

Investigaciones relacionadas con la motivación no consciente para generar empatía por comportamientos ambientalmente responsables encontraron que el uso de material audiovisual (documentales sobre naturaleza y biofilia) en jóvenes universitarios permitió evidenciar un cambio en su percepción emocional hacia los ambientes naturales después del estudio (Sánchez-Miranda \& De la Garza-González, 2015).

Ferreiro et al. (2013) compararon sus resultados haciendo énfasis en el género de los participantes del estudio. Las mujeres redujeron el consumo de bolsas en un $20 \%$, mientras que los hombres lo hicieron en un 7,5\%. Los autores concluyeron que en ese entorno las mujeres fueron más receptivas al estímulo visual. Estos resultados contrastan con los encontrados en el presente trabajo, en los que, para las dos fases, en los dos supermercados fue mayor el porcentaje de mujeres que llevaron bolsa, en relación con el porcentaje de hombres.

El análisis de los resultados de la encuesta realizada a los usuarios después de la compra evidenció que el $83 \%$ de la población conoce el impacto ambiental asociado al uso indiscriminado de bolsas plásticas. Estos resultados concuerdan con los obtenidos por Benavides-León y Ortiz (2013), en los que el $90 \%$ de los encuestados conocen la problemática. Sin embargo, en el mismo estudio solo un $36 \%$ de las personas encuestadas reutilizan las bolsas.

En el presente trabajo, el $72 \%$ de los consultados declararon reutilizar las bolsas plásticas, y estos datos son independientes del género, edad o nivel de escolaridad de los encuestados. Estos resultados son más cercanos al estudio realizado por Matusevich y Benayas (2011), quienes reportaron que un $97 \%$ de las 572 personas encuestadas reutiliza las bolsas plásticas que lleva a su casa, y un porcentaje muy pequeño (3\%) las tira a la basura.

Sin embargo, los datos recabados en el presente estudio indican que la población conoce los efectos medioambientales de sus comportamientos, pero no desarrollan hábitos que permitan disminuir ese impacto. Este tipo de resultados han sido previamente encontrados en otras comunidades, como en la comunidad Cassiano Lossada, Venezuela, donde se diseñó un programa comunitario ambiental para 30 familias, usando un cuestionario de 20 ítems con alternativas de respuestas cerradas y abiertas. Las autoras concluyeron que la comunidad está consciente de la problemática ambiental, pero no han generado organizaciones comunitarias o pedidos formales ante las instituciones competentes para tratar de buscar una solución a las problemáticas ambientales que las aquejan como comunidad (Valbuena-Reyes \& Araujo, 2007).

Si bien el efecto de una estrategia visual en el momento de la compra generó una reducción en el uso de bolsas plásticas de un solo uso, este podría haber sido mayormente significativo si los clientes hubieran estado preparados desde el momento de salir de su casa. Es decir, muchas personas en ese momento no podían rechazar una bolsa plástica, puesto que no llevaban consigo un medio para transportar los productos adquiridos, y además el supermercado o los cajeros no ofrecían una alternativa para reemplazar estos empaques altamente nocivos para nuestro planeta.

Los supermercados, como principal fuente de distribución de bolsas de plástico a las diferentes comunidades del municipio, no cuentan con planes de responsabilidad ambiental para mitigar el uso de estas, que propongan diferentes alternativas para sustituirlas o incentivar al usuario a reducir su uso. Además, los cajeros y empacadores de los supermercados Milca y Mercaexpress no son capacitados previamente en cuanto al tema, lo que influye significativamente en la decisión final del cliente de llevar o no la bolsa. 
Adriana Milena Bolívar-Lamus, Mónica Dayana Gamboa-Peña, Jenifer Dayana Granados-Núñez, María del Pilar Guauque-Torres Evaluación de una estrategia de sensibilización para desestimular el uso de bolsas plásticas en usuarios de supermercados del municipio

Diferentes autores coinciden en la importancia de diversificar las estrategias asociadas a la educación ambiental para lograr mayor efectividad en la modificación de los comportamientos asociados al cuidado del medioambiente. De hecho, la asociación entre palabras e imágenes no siempre guarda la relación esperada, y es necesario profundizar en el estudio para ampliar el conocimiento derivado de la investigación (Sánchez Miranda, De la Garza González \& Rangel Sandoval, 2013). Dentro de las múltiples estrategias planteadas para mejorar el comportamiento proambiental de la comunidad en general, el Estado colombiano, a través de la Ley 1819 de 2016, en su artículo 206, estipula el impuesto nacional al consumo de bolsas plásticas.

El trabajo desarrollado por Ayalon, Goldrath, Rosenthal y Grossman (2009) señaló que proveer al público en general con bolsas gratis cuando van de compras está directamente relacionado con su uso indiscriminado. Los mismos autores realizaron entrevistas a personajes clave dentro de la comunidad, así como encuestas al público en general, para identificar las actitudes de los entrevistados frente a la voluntad de pago de un impuesto por bolsa y la voluntad de cambiar los hábitos por un comportamiento proambiental. Se encontró que en el $94 \%$ de los encuestados existe una relación directamente proporcional entre la decisión de dejar de usar bolsas plásticas y el incremento del precio del impuesto asociado a su uso (cuanto más alto el impuesto, menor intención de uso). Sin embargo, se calcula que un impuesto típicamente usado que equivale a 0,28 USD solo reduce un $12 \%$ el uso de las bolsas plásticas. Los autores hicieron el análisis de las políticas públicas tendientes a la reducción del uso de bolsas plásticas en Israel y encontraron que la prohibición del uso de bolsas plásticas y la promoción del uso de bolsas biodegradables es una mejor política pública que la de establecer un impuesto. Los autores concluyeron que las políticas públicas de prohibición deben tener un fuerte componente educacional que motive al público en general para disminuir el uso de bolsas plásticas innecesarias (Ayalon, Goldrath, Rosenthal \& Grossman, 2009).

En este sentido, la educación ambiental debe promover múltiples estrategias didácticas conscientes e inconscientes que motiven a cambios en el comportamiento proambiental de la población en general $y$, de esta manera, se constituya en pilar fundamental para ayudar en la consecución de los 17 objetivos de desarrollo sostenible del Programa de Naciones Unidas (PNUD), en especial aquellos referidos a agua limpia y saneamiento (6), producción y consumo responsables (12), acción por el clima (13), vida submarina (14) y vida de ecosistemas terrestres (15) (Naciones Unidas, 2015).

\section{Agradecimientos}

A entidades como la Corporación Autónoma Regional (CAS) y la Universidad Libre (seccional Socorro), por su patrocinio en la actividad realizada en el sector San Victorino, haciéndose presentes con la donación de diferentes alternativas para sustituir el uso de las bolsas plásticas a la hora de hacer las compras.

De igual forma, al señor Juan Carlos Ardila Páez (gerente Sup. Mercaexpress) y a la señora Doralba Márquez Plata (gerente Sup. Milca), por concedernos la autorización para realizar las observaciones en las instalaciones de dichos supermercados; asimismo, al señor Wilson Chacón Franco (secretario de Tránsito Municipal), por permitir la ocupación del espacio público para la ejecución de la estrategia visual.

A las estudiantes Karen Ballesteros y Daniela Sanabria, por su contribución en la recolección de algunos de los datos consignados en el presente artículo.

\section{Referencias}

Alcaldía Municipal del Socorro Santander. (2018). Actualización e Implementación del Plan de Gestión Integral de Residuos Sólidos de Socorro Santander PGIRS 2015 - 2027. Recuperado de http://www. socorro-santander.gov.co/planes/actualizacion-eimplementacion-del-plan-de-gestion-integral

Ayalon, O., Goldrath, T., Rosenthal, G., \& Grossman, M. (2009). Reduction of plastic carrier bag use: An analysis of alternatives in Israel. Waste Management, 29(7), 20252032. https://doi.org/10.1016/j.wasman.2009.02.016

Benavides León, C. A., \& Ortiz, O. (2013). Estrategia de sensibilización para desestimular el uso de bolsas plásticas en los supermercados de Bogotá. Universidad Libre. Recuperado de https://repository.unilibre.edu. co/bitstream/handle/10901/10625/ESTRATEGIA. SENSIBILIZACION.DESESTIMULAR.BOLSAS. pdf? sequence $=1$ \&isAllowed $=y$

Dijksterhuis, A., Smith, P. K., Baaren, R. B. Van, Wigboldus, D. H. J., \& Link, P. (2005). The Unconscious Consumer : Effects of Environment on Consumer Behavior, 15(3), 193-202.

DNP, \& TECNALIA. (2017). Estudio en la intensidad de utilización de materiales y economía circular en Colombia para la misión de crecimiento verde. Recuperado de https://www.dnp.gov.co/CrecimientoVerde/Documents/ejes-tematicos/Circular/MATEC Producto 1_FINAL.pdf

Favara, J., Caballero, R. Y., Morici, J. F., \& Jakovcevic, A. (2013). Efectos conductuales de una política de precios para disminuir el uso de bolsas plásticas. In $\checkmark$ Congreso Internacional de Investigación y Práctica Profesional en Psicología XX Jornadas de Investigación Noveno Encuentro de Investigadores en Psicología 
Adriana Milena Bolívar-Lamus, Mónica Dayana Gamboa-Peña, Jenifer Dayana Granados-Núñez, María del Pilar Guauque-Torres Evaluación de una estrategia de sensibilización para desestimular el uso de bolsas plásticas en usuarios de supermercados del municipio del Socorro (Santander)

del MERCOSUR (p. 5). Buenos Aires. Recuperado de https://www.aacademica.org/000-054/12

Ferreriro, J., Putrino, N., Caballero, R., Moreno, C., StreikerDíaz, J., Franco, P., ... \& Jakovcevic, A. (2013). Suma psicologica. Suma Psicológica (Vol. 20). Fundación Universitaria Konrad Lorenz. Recuperado de http://www.scielo.org.co/scielo.php?script=sci_ arttext\&pid=S0121-43812013000100009

Hollman, V. (2009). (Cinco) Imágenes para analizar las miradas de la cuestión ambiental. Revista Geográfica, $145,47$.

Jain, S. K., \& Kaur, G. (2004). Green Marketing: An Attitudinal and Behavioural Analysis of Indian Consumers. Global Business Review, 5(2), 187-205. https://doi.org/10.1177/097215090400500203

Kusev, P., van Schaik, P., \& Aldrovandi, S. (2012). Preferences induced by accessibility: Evidence from priming. Journal of Neuroscience, Psychology, and Economics, 5(4), 250-258. https://doi.org/10.1037/ a0030289

Martinez, A. N., \& Porcelli, A. M. (2017). Consumo (in) Sostenible: Nuevos Desafíos Frente a la Obsolescencia Programada como Compromiso con el Ambiente y la Sustentabilidad. Ambiente y Sostenibilidad, 2016(6), 105. https://doi.org/10.25100/ays.v0i0.4294

Matusevich, V., \& Benayas, J. (2011). Percepción de los habitantes dela ciudad autónomadeBuenos Aires sobre el uso de bolsas plásticas. Universidad internacional de Andalucía. Recuperado de https://dspace.unia. es/bitstream/handle/10334/1836/0333_Matusevich. pdf? sequence $=1$

Ministerio de Ambiente y Desarrollo Sostenible. (2016). Resolución 668 del 28 de abril de 2016.

Naciones Unidas. (2015). Objetivos de Desarrollo Sostenible ODS. Onu, (Objetivos de Desarrollo Sostenible), 78. Recuperado de https://www.undp.org/content/undp/ es/home/sustainable-development-goals.html

Ohtomo, S., \& Ohnuma, S. (2014). Psychological interventional approach for reduce resource consumption: Reducing plastic bag usage at supermarkets. Resources, Conservation and Recycling, 84, 57-65. https://doi.org/10.1016/j. resconrec.2013.12.014

Presidencia de la República de Colombia (1991). Constitución Política de Colombia.

Presidencia de la República de Colombia. (1974). Decreto de ley 2811.

Romero-Ramírez, F. A., \& Vélez-Ledesma, C. D. (2011). Proyecto para un manejo adecuado de desechos sólidos en la comunidad de Marianza, Cantón Cuenca, Provincia Azuay. Técnica Particual de Loja - Escuela de Medicina. Recuperado de http://dspace.utpl.edu.ec/ bitstream/123456789/4818/1/Tesis_Flora-Romero.pdf

Sánchez Miranda, M. P., De la Garza González, A., \& Rangel Sandoval, M. L. (2013). Estudio sobre la valencia emocional de conceptos ambientales utilizando la técnica de facilitación afectiva. International Journal of Psychological Research, 6(2), 50-58. Recuperado de http://www.scielo.org.co/scielo.php?script=sci_ arttext\&pid=S2011-20842013000200006\&lng=en\&t Ing=en

Sánchez-Miranda, M., \& De la Garza-González, A. (2015). Biofilia y emociones: su impacto en un curso de educación ambiental. Revista lberoamericana de las Ciencias Sociales y Humanisticas: RICSH, 4(8), 123-143.

Seijas Rivera, K. S. (2018). "Técnicas de sensibilización ambiental en la reducción de bolsas comerciales de un solo uso en panaderías de ciudad satélite Santa Rosa, Callao 2017-2018." Universidad César Vallejo. Recuperado de http://repositorio.ucv.edu.pe/handle/ $\mathrm{UCV} / 24038$

Valbuena-Reyes, P. G., \& Araujo, M. (2007). Programa comunitario para la recolección de basura doméstica en la comunidad de Cassiano Lossada. Universidad Rafael Urdaneta. Recuperado de https://www. academia.edu/7398945/Andri

Vargas, L., Mensa, M., \& González, E. (2014). El uso de figuras retóricas en anuncios publicitarios y pinturas de Magritte: análisis sobre su efecto en la rememoración de marca en el corto plazo. Arte, Individuo y Sociedad, 26(1), 117-136. https://doi. org/10.5209/rev_ARIS.2014.v26.n1.41079

World Wide Foundation. (2017). Colombia adopta regulación a las bolsas plásticas |WWF. Recuperado de http://www.wwf.org.co/?304333/Colombia-regulabolsas-plasticas 